\title{
Effect of the Varying Percentage Diss Fiber on Mechanical Behaviour of the Based Polyester Bio-Composite
}

\author{
Lakhemissi Touam $^{1 *}$, Semcheddine Derfouf ${ }^{2}$ \\ ${ }^{1}$ LGM Mechanical Engineering Laboratory Biskra University, BP 145, Biskra 07000, Algeria \\ ${ }^{2}$ Faculty of Technological Sciences, University of Batna 2, Batna 05000, Algeria
}

Corresponding Author Email: lakhemissi.touam@univ-biskra.dz

https://doi.org/10.18280/rcma.310309

Received: 12 April 2021

Accepted: 5 June 2021

\section{Keywords:}

bio-composite, diss, polyester, treatment, mechanical characteristic

\begin{abstract}
Improving the mechanical and physical properties of bio-composite materials involves the incorporation of plant fibers such as Jute, Hemp, Kenaf, Ramie, Sisal, Linen, etc. The existence of Diss grass (Ampelodesmos mauritanicus) in abundance in the east of Algeria especially in Khenchela region and taking into account their mechanical resistance and their low density, which justifies their choice of use in composite materials. Tensile and hardness tests for different volume fractions (from 05\% to 20\%) of short fibers of Diss are performed. The increase in fiber content and their treatment improves the mechanical characteristics of the composite materials. These concentration levels are added to a Polyester resin matrix. Our work relates to the study of a composite material reinforced by a vegetable fiber of which different volume ratio of short Diss fiber are considered. The results collected are purely experimental.
\end{abstract}

\section{INTRODUCTION}

Currently the preservation of the environment and the use of renewable resources are the objectives to be achieved by all. The development of materials with renewable resources as reinforcement of composite materials are more and more used in several fields, in particular in industrial activities such as the automobile sector, textile, and furniture etc.

The mechanical properties of composite materials reinforced with vegetable fibers depend on several factors of which we quote: the fiber dosage i.e., the rate of fiber in the material, the length and orientation of these fibers. Several works have supported the use of plant fibers in organic matrices (thermoplastic, thermosetting) or in cement matrices, citing us: Diss [1, 2], Alfa [3], Kenaf [4-6], Lin [7, 8], Jute [9], Date palm [10, 11], Agave [12, 13], Pineapple Leaf [14, 15] Sisal [16].

Nouri et al. [17] in their work show that the Diss fiber bundles with slight diameter and rough surface with the presence of thorns and with low density shows a tensile strength that can reach $270 \mathrm{MPa}$. They also demonstrate that all the treatments adopted has demonstrated improvements regarding the fibrillation of fiber bundles, their surface state, their thermal stability and practically their mechanical behavior (could reach $+60 \%$ for Young's modulus and $+15 \%$ for tensile stress).

Sarasini et al. [18] In their work investigating about the morphology, the thermal, and mechanical properties of the Diss fibers by using an experimental process covering mechanical aspects, mild chemical, and enzymatic steps. They confirm that the structure of Diss fibres make them suitable as a reinforcing filler in polymer composites, which was assessed by manufacturing bio composites with improved stiffness and a tensile strength.

Ashok et al. [19] in their investigation have showed that the addition of nanofiller of Luffa could enhance the mechanical strength of the natural fiber composite.

Salem et al. [20], had studied the mechanical behaviour of Reinforced Alfa fibber with high density polyethylene composites strength by the tensile they showed that the tensile strength of the composites increased with the quantity of fiber in the composite.

Djoudi et al. [21] in their study related to the physical and mechanical characterizations of bio composite materials based on palm fibers, they have found that tensile strength tests of the bio composite material with different fiber percentages (04, 07,10 and $15 \%$ ) shows an improvement in the mechanical properties of the virgin resin proportional to the fiber mass ratio up to $10 \%$ while a degradation of these properties is detected for a fiber mass ratio of $15 \%$.

Nciri et al. [22] shows that when the polypropylene matrix is reinforced by the addition of short alfa fibers in the range of 05 and $15 \%$ by injection process, they found that composite behavior is sensitive to the strain rate, they also found that anisotropy increase when increasing fiber.

The problems related to the fiber / polyester interface because of the amorphous materials that the surface of the fiber contains are reduced by the different treatments, in our case study we used the alkaline treatment (with $\mathrm{NaOH}$ ) and consequently an improvement in the mechanical characteristics of the composite material is manifested. 


\section{EQUIPMENT USED}

\subsection{Metallizer}

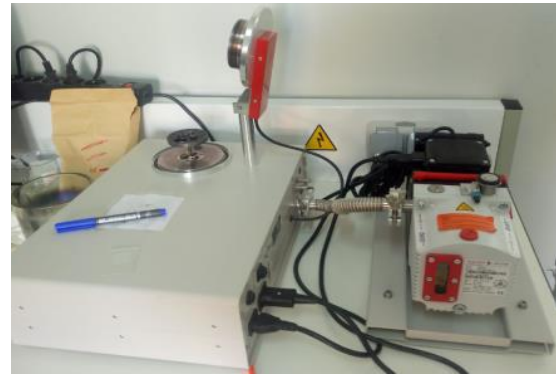

Figure 1. Metallizer

\subsection{Scanning electronique microscope}

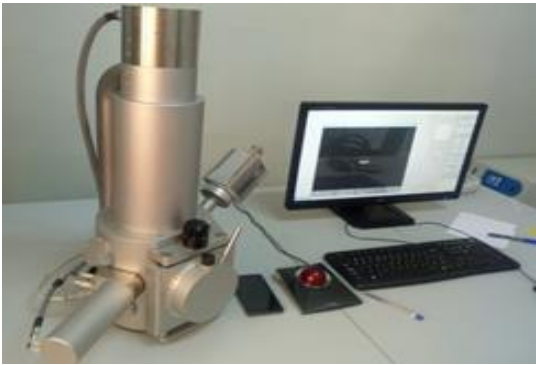

Figure 2. Scanning Electronique Microscope. TESCAN MARK VEGAS 3

\subsection{Traction machine}

Instron brand 5969 (Figure 3) controlled by a computer at a speed of $1 \mathrm{~mm} . \mathrm{mm}-1$ and at a temperature of $23^{\circ} \mathrm{C}$.

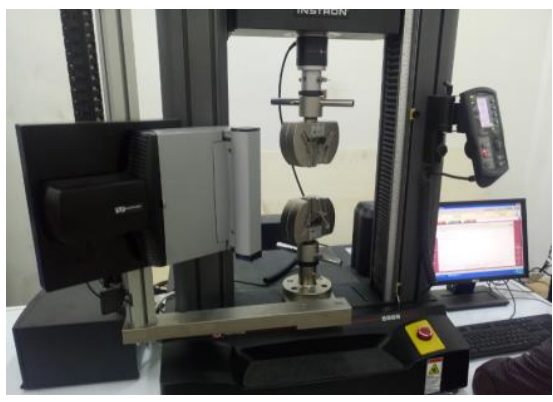

Figure 3. Instron 6959 brand traction machine

\subsection{Micro-hardness Tester}

HBVR - 187,5 as shown in Figure 4.

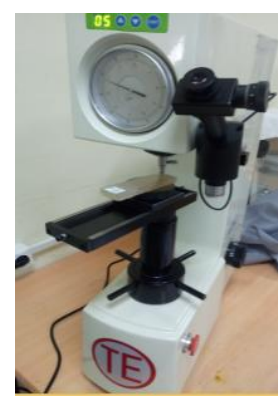

Figure 4. Hardness Tester

\section{RESULTS}

\subsection{Observations to the scanning electronic microscope}

The samples of the different fibers are observed with the ESM (Figure 2) after metallization to make their surfaces conductive (Figure 1), the use of this distinction leads to deducing the morphology and the measurements of the fibers.

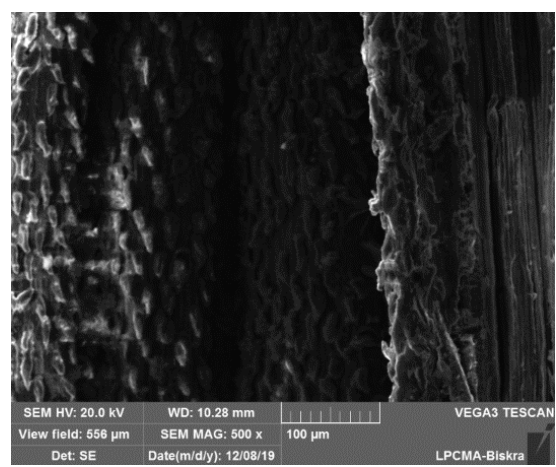

(a)

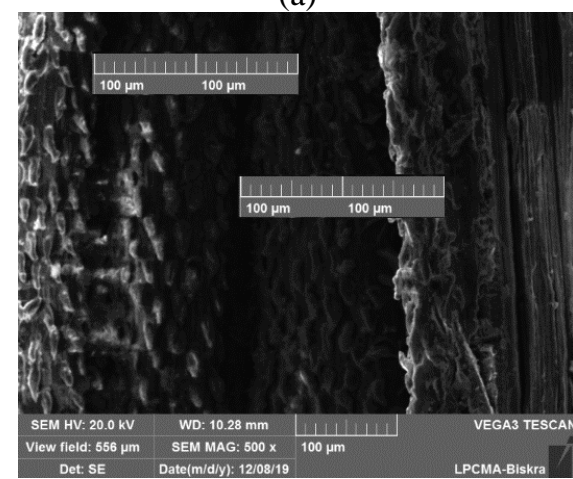

(a')

Figure 5. (a, a') SEM micrograph in longitudinal view of Diss fiber in its raw state

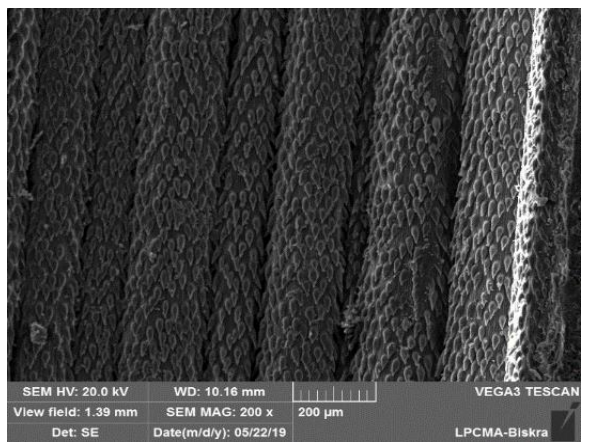

(b)

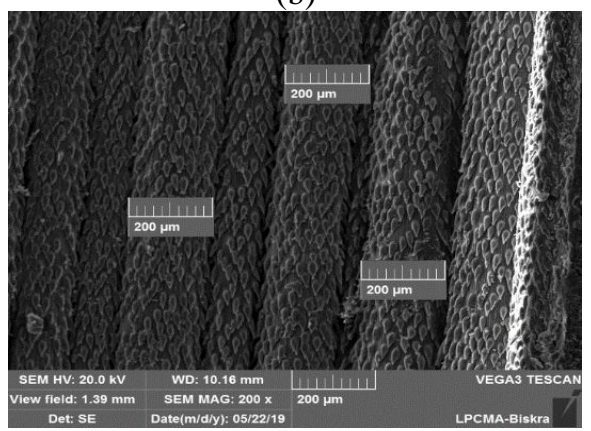

(b')

Figure 6. (b b') SEM micrograph in longitudinal view of Diss fiber after treatment with $\mathrm{NaOH}$ 


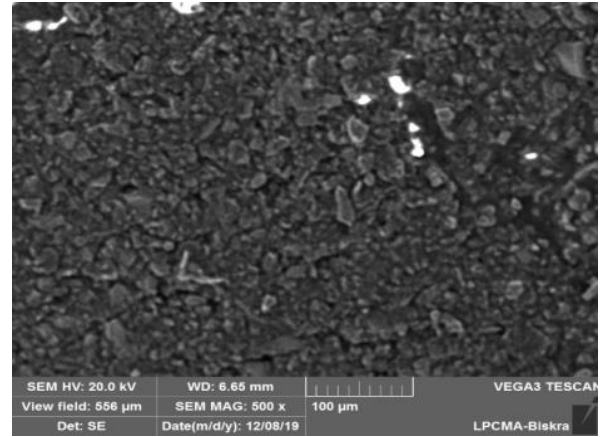

Figure 7. SEM micrograph transverse view of Diss fiber in its raw state

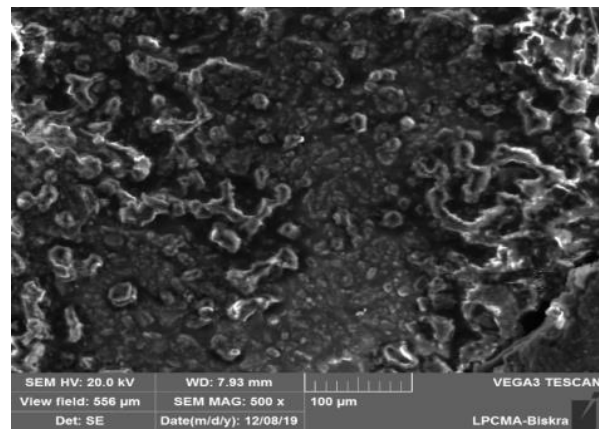

Figure 8. SEM micrograph transverse view of Diss fiber after treatment with $\mathrm{NaOH}$

Figures 5 to 8 Illustrate the difference between Diss fibers in their raw and processed states. The surfaces of the raw fibers are smooth because of the wax and cellulosic component, on the other hand the treated fibers have rough surfaces of snakeskin.

The figure a 'and b' are exposed to justify the measurements of the diameters of the fibers.

\subsection{Traction test}

The traction test is the most used for the characterization of materials to deduce their mechanical parameters, this test consists in subjecting a specimen to a unidirectional traction force until failure.

This test allows to study in detail the influence of the additions of fibers to the matrix and to observe the evolution of the mechanical characteristics of the bio-composite material.

\subsubsection{Production of test Specimens}

The traction specimens are cut according to the ISO 527-2 B1 standard (Figures 9, 10 and 11), these specimens have different volume fraction as a percentage of fibers. The specimens are on average six specimens for each type of test.

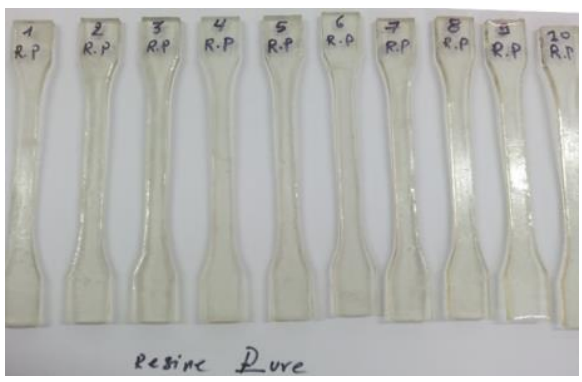

Figure 9. Tensile specimens in Polyester resin

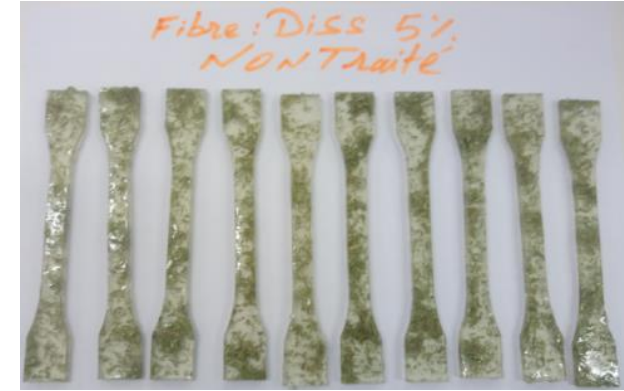

Figure 10. Tensile specimens reinforced with $05 \%$ untreated Diss fiber

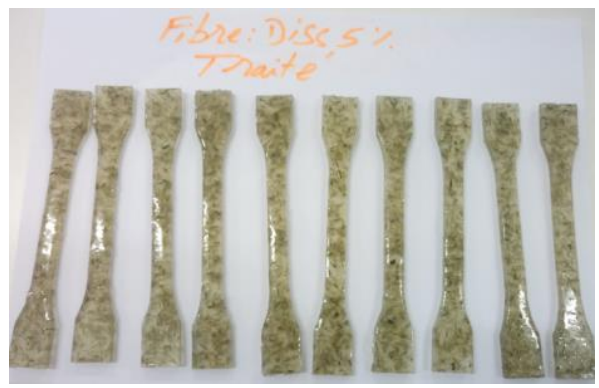

Figure 11. Tensile specimens reinforced with $05 \%$ treated Diss fiber

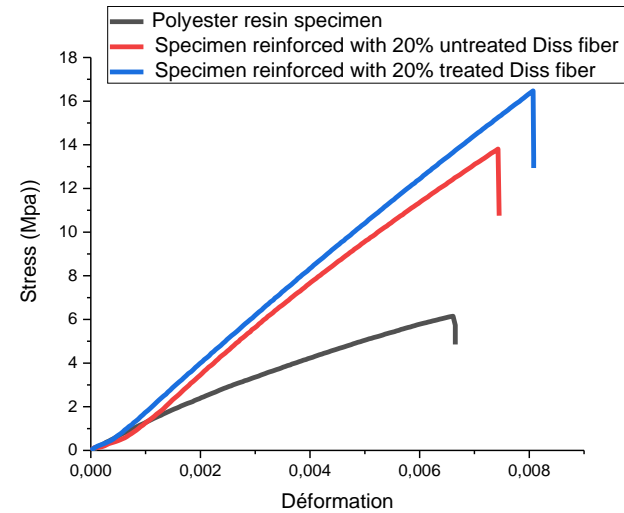

Figure 12. Stress-strain curve of the resin and at $20 \%$ of treated and untreated Diss fibers

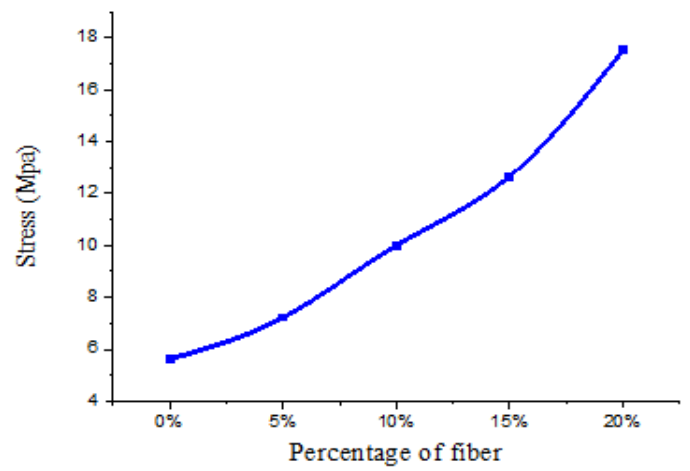

Figure 13. Variation of the stress at break as a function of the fiber rate of Diss

The stress-strain curves of (Figure 12) represent an example of the results obtained from the tensile test on the reference specimen (Polyester resin) and two specimens with a volume content of $20 \%$ of fibers of Diss treated and untreated (Figures $13,14)$. 


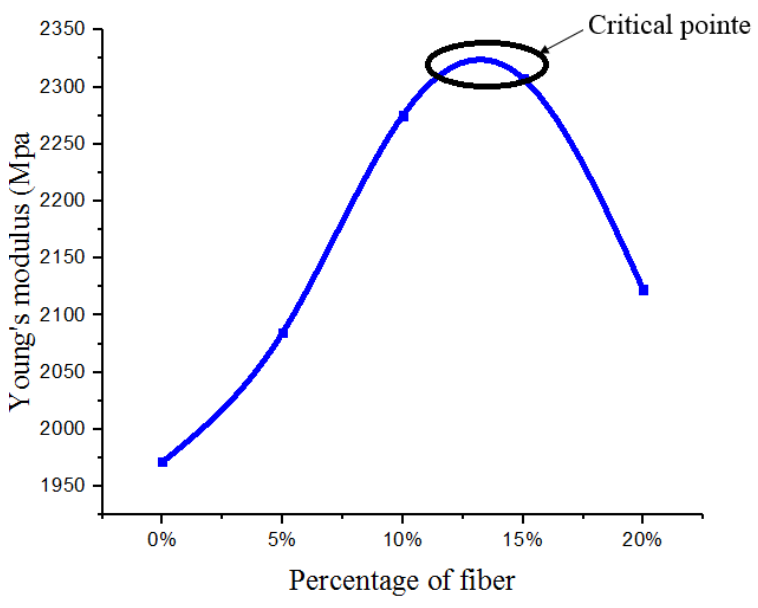

Figure 14. Variation of the Young's modulus $\mathrm{E}$ as a function of the fiber rate of Diss (from $0 \%$ to $20 \%$ )

Note: Given the decrease in the value of Young's modulus for the range of $(15 \%-20 \%)$, which presents a degradation of the matrix's material, we limi the study to the range of the volume fraction (from $0 \%$ to $15 \%$ ) (Figure 15).

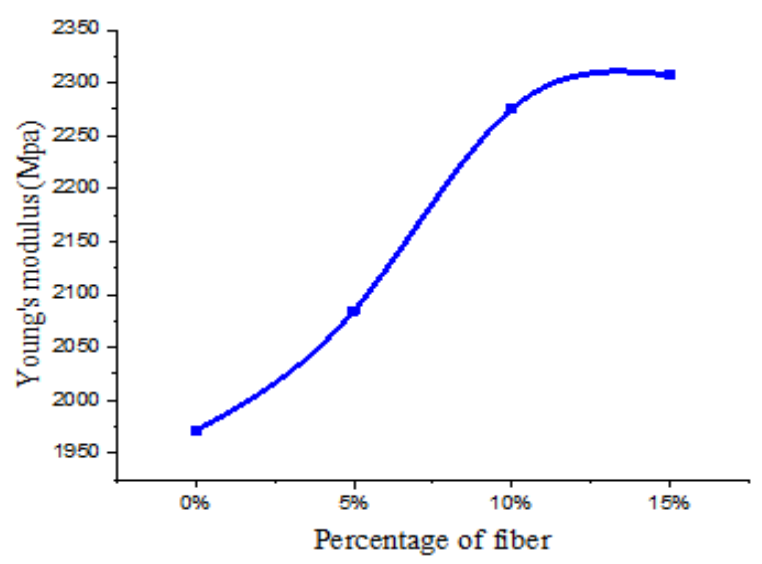

Figure 15. Variation of the Young's modulus $E$ as a function of the fiber rate of Diss $(0 \%-15 \%)$

\subsection{Hardness test}

The hardness tests are made to know some properties of the material such as its ductility and resistance to penetration. They are carried out by an HBRV-187,5 Hardness Tester (Figure 4). These tests are carried out for test pieces with different percentage of Diss fiber content in their raw and processed states. Four specimens for each type of material are tested. Six measurements are taken for each specimen, therefore 26 readings for the same specimen. Brinell hardness value is given by predefined tables (Tables 1 and 2) after calculating the product of the difference in reading on the microscope multiplied by the amplification coefficient of the microscope.

$$
\mathrm{L}=\left(\mathrm{L}_{\mathrm{MAX}}-\mathrm{L}_{\mathrm{MIN}}\right) \mathrm{I} \rightarrow \mathrm{HB}
$$

$\mathrm{I}=0.004$ when the objective is $2.5 \mathrm{x}$.

$\mathrm{I}=0.002$ when the objective is $5 \mathrm{x}$.

We can also calculate the Brinell hardness by the following expression:

$$
H B=\frac{2 f}{\pi D\left(D-\sqrt{D^{2}}-d^{2}\right)} 0,102
$$

Table 1. Brinell hardness values for a specimen at a rate of

\begin{tabular}{|c|c|c|c|}
\hline \multicolumn{4}{|c|}{ Specimen numberTest numberHB CalculatedHB given } \\
\hline \multirow{6}{*}{01} & 01 & 26.5738 & 27.060 \\
\hline & 02 & 31.2200 & 31.800 \\
\hline & 03 & 22.0022 & 22.436 \\
\hline & 04 & 27.1612 & 27.680 \\
\hline & 05 & 33.8459 & 34.400 \\
\hline & 06 & 23.9708 & 24.440 \\
\hline \multirow{6}{*}{02} & 01 & 28.4978 & 29.700 \\
\hline & 02 & 25.8179 & 26.360 \\
\hline & 03 & 28.3917 & 28.090 \\
\hline & 04 & 30.1578 & 30.760 \\
\hline & 05 & 29.7021 & 30.260 \\
\hline & 06 & 20.8574 & 21.260 \\
\hline \multirow{6}{*}{03} & 01 & 25.2705 & 25.740 \\
\hline & 02 & 24.1387 & 24.600 \\
\hline & 03 & 30.6235 & 31.200 \\
\hline & 04 & 29.8151 & 30.380 \\
\hline & 05 & 29.7585 & 30.300 \\
\hline & 06 & 29.3112 & 29.880 \\
\hline \multirow{6}{*}{04} & 01 & 22.0022 & 22.440 \\
\hline & 02 & 19.6008 & 19.900 \\
\hline & 03 & 27.0620 & 27.560 \\
\hline & 04 & 28.2862 & 28.820 \\
\hline & 05 & 24.1387 & 24.600 \\
\hline & 06 & 25.3312 & 25.660 \\
\hline
\end{tabular}
$20 \%$ of Diss fibers

Table 2. Average values of hardness for each type of

\begin{tabular}{|c|c|c|c|}
\hline Specimen & $\begin{array}{c}\text { Test } \\
\text { number }\end{array}$ & $\begin{array}{c}\text { Average values of } \\
\text { hardness }\end{array}$ & $\begin{array}{l}\text { Specimen's Average } \\
\text { values of hardness }\end{array}$ \\
\hline \multirow{4}{*}{$0 \%$} & 01 & 19.3098 & \multirow{4}{*}{18.8436} \\
\hline & 02 & 18.0453 & \\
\hline & 03 & 19.2854 & \\
\hline & 04 & 18.7341 & \\
\hline \multirow{4}{*}{$5 \%$} & 01 & 21.1733 & \multirow{4}{*}{22.3700} \\
\hline & 02 & 22.3656 & \\
\hline & 03 & 24.1993 & \\
\hline & 04 & 21.7417 & \\
\hline \multirow{4}{*}{$10 \%$} & 01 & 24.1578 & \multirow{4}{*}{24.9071} \\
\hline & 02 & 25.1338 & \\
\hline & 03 & 23.9764 & \\
\hline & 04 & 26.3604 & \\
\hline \multirow{4}{*}{$15 \%$} & 01 & 26.3232 & \multirow{4}{*}{26.2257} \\
\hline & 02 & 24.5882 & \\
\hline & 03 & 25.5681 & \\
\hline & 04 & 28.4234 & \\
\hline \multirow{4}{*}{$20 \%$} & 01 & 28.2176 & \multirow{4}{*}{27.8159} \\
\hline & 02 & 29.0632 & \\
\hline & 03 & 26.7600 & \\
\hline & 04 & 27.2227 & \\
\hline
\end{tabular}
specimen

\section{EVOLUTION OF TENSILE AND BRINELL HARDNESS TEST}

Table 3. Summary of tensile and Brinell hardness test results

\begin{tabular}{cccc}
\hline $\begin{array}{c}\text { Percentage of } \\
\text { fiber (\%) }\end{array}$ & $\begin{array}{c}\text { Young's } \\
\text { Modulus }\end{array}$ & $\begin{array}{c}\text { Elastic limit } \\
\text { (Mpa) }\end{array}$ & $\begin{array}{c}\text { Brinell } \\
\text { hardness }\end{array}$ \\
\hline $0 \%$ & 1971.4575 & 5.6357 & 18.8436 \\
\hline $05 \%$ & 2084.6672 & 7.2256 & 22.3700 \\
\hline $10 \%$ & 2275.1158 & 10.0025 & 24.9071 \\
\hline $15 \%$ & 2307.4627 & 12.6573 & 26.2257 \\
\hline $20 \%$ & 2122.4578 & 17.5084 & 27.8159 \\
\hline
\end{tabular}


In this part we expose some results of tensile and Brinell hardness characterization of our bio composite specimens, as shown in Table 3.

\section{DISCUSSIONS OF RESULTS}

The two Figures 13 and 14 show that the density fractions increase of diss fibers in the polyester matrix improves the strength and modulus of elasticity.

Concerning the hardness testing, by analyzing the measurements of the various tests carried out, we can say that on average the hardness values increase as a function of the volume rates of the Diss fibers (Figure 16), this increase is linked to the hardness of the fibers. It is also noted that the values of the Brinell hardness are not stable for the simple reason that the indentor sinking depends on the contact zone. These values vary depending on whether the fiber is very near or far from the pressure zone. Because the fiber of Diss is considered more rigid and therefore opposes the indenter. The hardness is stable around $19 \mathrm{HB}$ for the resin, on the other hand there is a high probability of having values greater than $25 \mathrm{HB}$ and a low probability of having values below $25 \mathrm{HB}$ for a volume fraction of fiber greater than $20 \%$. On the contrary, there is a high probability of having values of about $20 \mathrm{HB}$ and a low probability of having values greater than $25 \mathrm{HB}$ for volume fractions of less than $10 \%$.

The evolution of the Brinell hardness values as a function of the elastic limit and the evolution of these same values as a function of Young's modulus are proportional and in agreement (Figure 17) and (Figure 18).

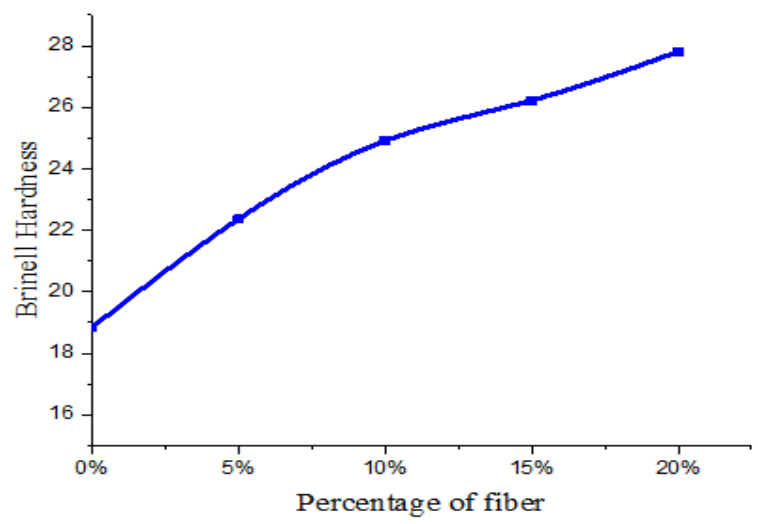

Figure 16. Change in Brinell hardness with volume fraction of Diss fibers

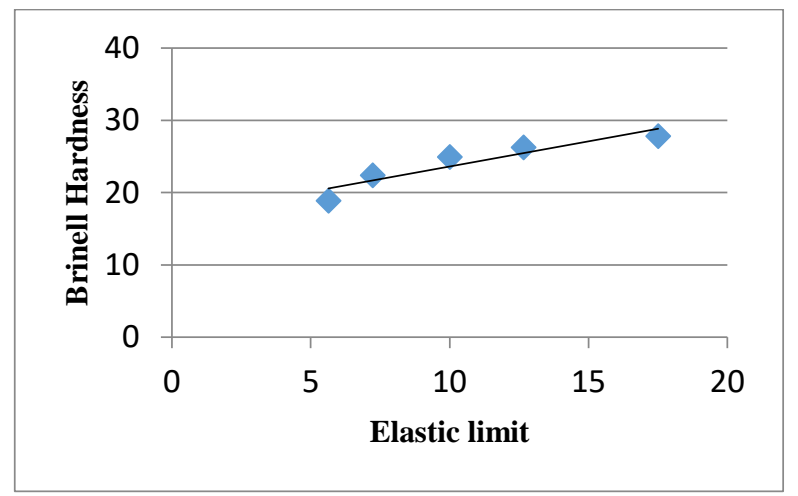

Figure 17. Evolution of Brinell hardness and elastic limit

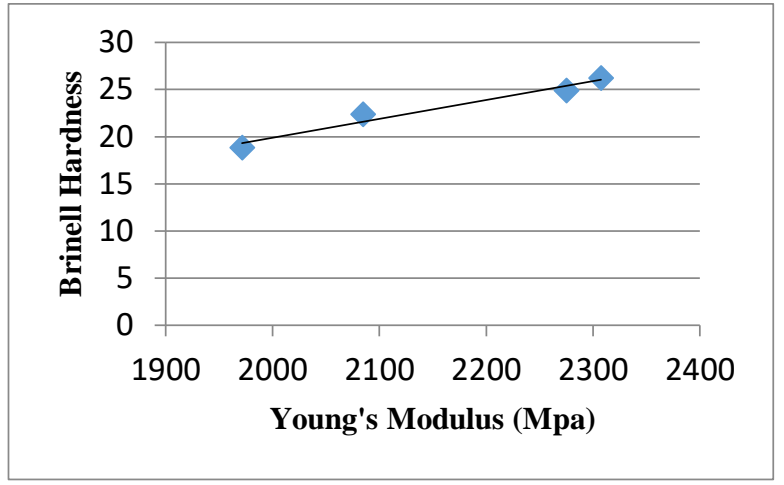

Figure 18. Evolution of Brinell hardness and Young's Modulus

\section{CONCLUSION}

Following the results presented in the case of our study which stipulates the variation of the percentage of Diss fiber in the Polyester matrix we conclude:

Relating to Figures 5 and 6 which represent scanning electron microscopy images containing Diss fibers in their states before and after treatment with $\mathrm{NaOH}$, we deduce that the fiber volume increases diametrically due to the absorption of liquid $\mathrm{NaOH}$ solution. This increase is evaluated at a quarter of its initial volume.

The impact of the indenter is greater in the surface containing just resin than on the surface containing fiber, which explains the increase in the hardness value in the presence of the Diss fiber.

The increase in mechanical parameters such as: Young's modulus E, stresses and strains is proportional to the increase in the rate of Diss fibers.

\section{REFERENCES}

[1] Bourahli, M.E.H., Osmani, H. (2013). Chemical and Mechanical Properties of Diss (Ampelodesmos mauritanicus) Fibers. Journal of Natural Fibers, 10(3): 219-232. https://doi.org/10.1080/15440478.2012.761115

[2] Bourahli, M.E.H. (2017). Uni and bimodal Weibull distribution for analyzing the tensile strength of Diss fibers. Journal of Natural Fibers, (IF2.622): 843-852. https://doi.org/10.1080/15440478.2017.1371094

[3] El-Abbassi, F.E., Assarar, M., Ayad, R., Bourmaud, A., Baley, C. (2020). A review on alfa fibre (Stipa tenacissima L.) from the plant architecture to the reinforcement of polymer composites. Composites Part A: Applied Science and Manufacturing, 128: 105677. https://doi.org/10.1016/j.compositesa.2019.105677

[4] Sreenivas, H.T., Krishnamurthy, N., Arpitha, G.R. (2020). A comprehensive review on light weight kenaf fiber for automobiles. International Journal of Lightweight Materials and Manufacture, 3(2020): 328337. https://doi.org/10.1016/j.ijlmm.2020.05.003

[5] Ramesh, M. (2016). Kenaf (Hibiscus cannabinus L.) fibre based bio-materials: A review on processing and properties Progress in Materials Science, 78-79: 1-92. https://doi.org/10.1016/j.pmatsci.2015.11.001

[6] Khana, A., Vijay, R., Lenin, D.S., Arpitha, G.R., Sanjay, 
M.R., Siengchin, S., Jawaid, M., Alamry, K., Abdullah M.A. (2019). Extraction and characterization of vetiver grass (Chrysopogon zizanioides) and kenaf fiber (Hibiscus cannabinus) as reinforcement materials for epoxy based composite structures. Journal of Materials Research and Technology, 9(1): 773-778. https://doi.org/10.1016/j.jmrt.2019.11.017

[7] Toupe, J.L. (2015). Optimisation des propriétés mécaniques de composites à base de fibres naturelles: Application à un composite de fibre de lin avec un mélange de polyéthylène/polypropylène d'origine postconsommation. Thèse de Doctorat, Université Laval Québec,Canada.

http://hdl.handle.net/20.500.11794/25985

[8] Pantaloni, D., Shah, D., Baley, C., Bourmaud, A. (2020). Monitoring of mechanical performances of flax nonwoven biocomposites during a home compost degradation. Polymer Degradation and Stability, 177: 109166.

https://doi.org/10.1016/j.polymdegradstab.2020.109166

[9] Saha, P. Manna, S., Chowdhury, S.R., Sen, R., Debasis Roy, Adhikari, B. (2010). Enhancement of tensile strength of lignocellulosic jute fibers by alkali-steam treatment. Bioresource Technology, 101(2010): 31823187. https://doi.org/10.1016/j.biortech.2009.12.010

[10] Saba, N., Alothman, O.Y., Almutairi, Z., Jawaid, M., Ghori, W. (2019). Date palm reinforced epoxy composites: tensile, impact and morphological properties. Journal of Materials Research and Technology, 8(5): 3959-3969. https://doi.org/10.1016/j.jmrt.2019.07.004

[11] Dhakal, H., Bourmaud, A., Berzin, F., Almansour, F., Zhang, Z., Shah, D.U., Beaugrand, J. (2018). Mechanical properties of leaf sheath date palm fibre waste biomass reinforced polycaprolactone (PCL) biocomposites. Industrial Crops and Products, 126: 394-402. https://doi.org/10.1016/j.indcrop.2018.10.044

[12] Msahli, S., Jaouadi, M., Sakli, F., Drean, J.Y. (2015). Study of the mechanical properties of fibers extracted from Tunisian Agave americana L. Journal of Natural Fibers, 12(6): https://doi.org/10.1080/15440478.2014.984046

[13] Bezazi, A., Belaadi, A., Bourchak, M., Scarpa, F., Boba, K. (2014). Novel extraction techniques, chemical and mechanical characterisation of Agave americana L. natural fibres. Composites Part B: Engineering, 66: 194203. https://doi.org/10.1016/j.compositesb.2014.05.014

[14] Yogesh, M., Hari, R.A.N. (2017). Study on pineapple leaves fibre and its polymer based composite: A review. Int. J. Sci. Res, 6: 799-807. https://doi.org/10.21275/ART20164188

[15] Teles, M.C.A., Glória, G.O., Altoé, G.R., Amoy, P., Margem, F.M., Braga, F.O., Monteiro, S.N. (2015). Evaluation of the diameter influence on the tensile strength of pineapple leaf fibers (PALF) by Weibull method. Materials Research, 18: 185-192. https://doi.org/10.1590/1516-1439.362514

[16] Ibrahim, I.D., Jamiru, T., Sadiku, E.R., Kupolati, W.K., Agwuncha, S.C., Ekundayo, G. (2016). Mechanical properties of sisal fibre-reinforced polymer composites: A review. Composite Interfaces, 23(1): 15-36. https://doi.org/10.1080/09276440.2016.1087247

[17] Nouri, M., Griballah, I., Tahlaiti, M., Grondin, F., Beaugrand, J. (2019). Plant extraction and physicochemical characterizations of untreated and pretreated diss fibers (Ampelodesmos mauritanicus). Journal of Natural Fibers, 1-11. https://doi.org/10.1080/15440478.2019.1687062

[18] Sarasini, F., Tirillò, J., Maffei, G., Zuorro, A., Lavecchia, R., Luzi, F., Maghchiche, A. (2019). Thermal and mechanical behavior of thermoplastic composites reinforced with fibers enzymatically extracted from Ampelodesmos mauritanicus. Polymer Engineering \& Science, 59(12): 2418-2428. https://doi.org/10.1002/pen.25093

[19] Ashok, K.G., Kalaichelvan, K., Damodaran, A. (2020). Effect of Nano Fillers on Mechanical Properties of Luffa Fiber Epoxy Composites. Journal of Natural Fibers, 1-18. https://doi.org/10.1080/15440478.2020.1779898

[20] Salem, S., Oliver-Ortega, H., Espinach, F.X., Hamed, K. B., Nasri, N., Alcalà, M., Mutjé, P. (2019). Study on the tensile strength and micromechanical analysis of alfa fibers reinforced high density polyethylene composites. Fibers and Polymers, 20(3): 602-610. https://doi.org/10.1007/s12221-019-8568-X

[21] Djoudi, T., Hecini, M., Scida, D., Djebloun, Y., Djemai, H. (2021). Physico-mechanical characterization of composite materials based on date palm tree fibers. Journal of Natural Fibers, 18(6): 789-802. https://doi.org/10.1080/15440478.2019.1658251

[22] Nciri, M., Notta Cuvier, D., Lauro, F., Chaari, F., Delille, R., Haugou, G., Zouari, B. (2019). Performance over a wide range of strain rate of polypropylene reinforced by short alfa fibers. Polymer Composites, 40(7): 2850-2862. https://doi.org/10.1002/pc.25108 